\section{CASE OF ACUTE GASTRITIS.}

To the Edilor of The LANCET. SIR,-Having read in the last number of your valuable periodical a fatal case of vomiting and purging by Mr. Leigh, the diagnosis of which appeared to the medical attendant very obscure, even after a postmortem examination, perhaps the follow. ing case, which occurred to me a short time back, and was very similar to the one related, may explain the cause of death without much difficulty.

Sarah Baker, ætat. 30, a deaf and dumb person, an inmate of the Croydon Union, was enceinte of her second illegitimate child, and expected to be confined daily. She was taken ill on Wednesday, the $20 \mathrm{th}$ of December, with retching and constant sickness. The os uteri was dilated to about the size of a shilling, and it was expected that labour had commenced, and that the sickness was merely the usual attendant symptom of parturition.

Effervescing salines, with opiates, were given, but did not allay the sickness. The labour did not progress, but for the three following days the vomiting of bilious matter was incessant. Nothing was retained on the stomach for one minute. The disease had now assumed a most alarming form, and active treatment was called for. The pulse was very feeble, surface cold, anxious expression of countenance, and tongue coated. The diagnosis of acute gastritis was clearly made out. Leeches were applied to the epigastric region and followed by a blister. Hydrocyanic acid, creosote, opium, morphia, and all the appropriate remedies, were not of the slightest avail, and she died on the fourth day, the vomiting having never ceased until a few hours before death. The post-mortem proved the correctness of the diagnosis. The stomach was in a high state of inflammation, but all the other viscera healthy. The os uteri was not more dilated than at first, and the uterus contained a perfect nine-month's child, - presentation natural.

Now, Mr. Leigh also finds the stomach inflamed, which, with the symptoms present during life, constitute that rather rare form of disease, idiopathic gastritis. But is there any such mystery in the case after what the autopsy had revealed, as to require one to ask, What was the cause of death? What clearer cause would anybody wish to find than an inflammation of the most important organ in the whole human frame. The palpitation of the heart was most probably sympathetic. Local depletion was indicated to a considerable extent, notwithstanding the almost imperceptible state of pulse, a usual occurrence in acute gastritis. I cannot see that the blister evidently did harm, although it might not have relieved her, for it certainly would be indicated in the modus curandi. I should not have troubled you with these remarks had not your correspondent courted an inquiry, and asked three times repeatedly, in relating the case, Was the inflammation of the stomach sufficient to account for death? Undoubtedly it was; and I should add, that the case, far from presenting anything novel, is as clear a one as any practitioner might have to treat.

It may be a rare one, as idiopathic acute gastritis, proving fatal, is seldom met with, but it is certainly not a novel one. The case I have reported being very similar, and having occurred to me so recently, I thought it might not be uninteresting to your readers. I am, Sir, your most obedient servant,

J. BeR NCAstLe,
Croydon, Feb. 20, 1844.

*** The anomaly of Mr. Leigh's case (see Lancet, p. 687) appears to us to have consisted in the presence of violent diarrbœa, diarrhoea not being a symptom of gastritis. Mr. Leigh states that the intestinal canal was healthy, and yet the purging was incessant during the last six days of the patient's life, constituting a choleric flux, if we may so term it. How was it that our correspondent did not endeavour to deliver his patient? It seems, from his account, that she was in the ninth month of her pregnancy, and that the os uteri had begun to dilate.

\section{REVIEW}

of $A$

\section{MEMIOIR ON FEIGNED DISEASE BY}

\section{OLLIVIER D'ANGERS.}

M. Ollivier D'Angers proposes, in a memoir recently published in the "Annales d'H y giène et de Médecine Légale," to divide feigned diseases into three classes, each of which he illustrates by several cases. The first class comprises pretexed or supposed diseases; the second, induced diseases; and the third, simulated or feigned diseases, properly so called. We will briefly analyse the data on which he founds each of these divisions, illustrating them by one or two of his most interesting cases.

\section{PRETEXED DISEASES.}

Pretexed diseases (says MI. Ollivier) are generally those maladies which present no material symptom during their existence, and leave no material trace of their previous existence when passed; such are, for instance, slight sciatica, lumbago, and other rheumatic affections. In these diseases, the symptoms not being materially appreciable by the medical man, if the patient is well acquainted with the symptoms which he says 